\title{
EFEITO DE DIFERENTES SUBSTRATOS NA GERMINAÇÃO E NO DESENVOLVIMENTO INICIAL DE JILOEIRO (Solanum gilo RADDI), CULTIVAR VERDE CLARO
}

\author{
Effect of different substrata in the germination of seeds and initial growing of jilo \\ (Solanum gilo RADDI), CV. verde claro
}

\author{
Bruno Galvêas Laviola ${ }^{1}$, Priscila Alves Lima ${ }^{2}$, Américo Wagner Júnior ${ }^{1}$, Aldo Luíz Mauri', \\ Ronaldo S. Viana ${ }^{3}$, José Carlos Lopes ${ }^{4}$
}

\begin{abstract}
RESUMO
Objetivou-se com este trabalho avaliar o efeito de diferentes substratos na germinação e no desenvolvimento inicial de jiló ( $S$. gilo Raddi), cultivar Verde-Claro. Foi utilizado o delineamento estatístico inteiramente casualizado com quinze tratamentos, quatro repetições, considerando-se como unidade experimental 100 sementes. Os tratamentos consistiram na utilização dos substratos: resíduos de mineração de calcário com NPK adicional (S1), resíduos de mineração de calcário com NPK e lodo adicional (1:1 v/v) (S2), resíduos de mineração de calcário com NPK e esterco bovino adicional (1:1 v/v) (S3), resíduos de mineração de calcário com NPK e composto orgânico adicional (1:1 v/v) (S4), argissolo vermelho-amarelo com calagem e NPK adicional (S5), argissolo vermelho-amarelo com calagem, NPK e lodo adicional $(1: 1 \mathrm{v} / \mathrm{v})(\mathrm{S} 6)$, argissolo vermelho-amarelo com calagem, NPK e composto orgânico adicional (1:1 v/v) (S7), argissolo vermelho-amarelo com calagem, NPK e esterco bovino adicional (1:1 v/v) (S8), argissolo (pastagem) (S9), solo de várzea (S10); areia lavada (S11), cambissolo haplico eutrófico (S12), substrato comercial (Plantmax ${ }^{\mathrm{R}}$ (S13), resíduos de mineração de calcário (S14) e argissolo vermelho-amarelo eutrófíco (S15). Aos 18 dias, avaliaram-se: porcentagem de germinação, índice de velocidade de emergência, massa da matéria fresca da parte aérea e da radícula e massa da matéria seca da parte aérea e da radícula. Os substratos que apresentaram os melhores resultados de germinação das sementes foram argissolo vermelho-amarelo com calagem, NPK e esterco bovino adicional, solo de várzea e cambissolo haplico eutrófico. Entretanto, o substrato comercial Plantmax ${ }^{\mathrm{R}}$ foi o melhor substrato na produção da massa da matéria seca das plântulas.
\end{abstract}

Termos para indexação: Jiloeiro, propagação sexuada, vigor.

\begin{abstract}
The aim of this work was to evaluate the effect of different substrates in the germination and the initial growing of garden egg seeds (S. gilo Raddi), cv. Verde Claro. The experimental design was in completely randomized design, with fifteen treatments and four replications of one hundred seeds per plot. The treatments consisted of the use of substrates: residues of limestone mining with additional NPK (S1), residues of limestone mining with NPK and additional mud (1:1 v/v) (S2), residues of limestone mining with NPK and additional manure (1:1 v/v) (S3), residues of limestone mining with NPK and composed organic additional (1:1 v/v) (S4), red-yellow argisoil with liming and additional NPK (S5), red-yellow argisoil with liming, NPK and additional mud (1:1 v/v) (S6), redyellow argisoil with liming, NPK and composed organic additional (1:1 v/v) (S7), red-yellow argisoil with calagem, NPK and additional manure (1:1 v/v) (S8), argisoil (pasture) (S9), meadow soil (S10); washed sand (S11), cambissolo eutrophic halico (S12), commercial substrate $\left(\right.$ Plantmax $\left.^{R}\right)(\mathrm{S} 13)$, residues of limestone mining (S14) and argisoil red-yellow eutrófíco (S15). After 18 days the following parameters were evaluated: germination percentage; emergence speed; mass of the fresh matter of the aerial part and of the radicule and mass of the matter drought of the aerial part and of the radicule. The best substrate used in the seeds germination were red-yellow argisoil with liming, NPK and additional manure, meadow soil and cambissolo eutrophic halico. However, the commercial substrate Plantmax ${ }^{\mathrm{R}}$ was the best substrate in the production of the mass of the matter drought of the plantlets.
\end{abstract}

Index terms: Garden egg plant, sexual propagation, vigor.

(Recebido para publicação em 3 de dezembro de 2004 e aprovado em 10 de outubro de 2005)

\section{INTRODUÇÃO}

Originário da Índia ou da África e introduzido no Brasil pelos escravos, o jiloeiro (Solanum gilo Raddi) é uma hortaliça fruto tipicamente tropical, muito exigente em calor (FILGUEIRA, 1987). É bastante cultivado no Brasil, principalmente, nos Estados do Rio de Janeiro, Minas Gerais, Espírito Santo e São Paulo (PESAGRO-RIO \& EMATER-RIO, 1989).

O plantio de jiló é feito por meio de transplante de mudas obtidas por sementes (BLANCO et al., 1997). A germinação é afetada por uma série de condições extrínsecas,

\footnotetext{
${ }^{1}$ Engenheiro Agrônomo - Doutorado - Fitotecnia - Universidade Federal de Viçosa/UFV - Bolsista CNPq - laviolabg@yahoo.com.br

${ }^{2}$ Engenheiro Agrônomo - Mestrado - Solos - Universidade Federal de Pernambuco/ UFPE - priscilaea@hotmail.com

${ }^{3}$ Graduando em Agronomia - Universidade Federal do Espírito Santo/UFES.

${ }^{4}$ Engenheiro Agrônomo - Professor do Centro de Ciências Agrárias/CCA - Universidade Federal do Espírito Santo/UFES.
} 
cujo conjunto é essencial para que o processo se realize normalmente (TOLEDO \& MARCOS FILHO, 1977).

Para o bom desenvolvimento de qualquer cultura, é de fundamental importância a utilização de sementes e mudas de boa qualidade, tornando-se necessário o estudo de métodos de produção de jiloeiro que resultem em plantas com qualidade agronômica necessária para plantios comerciais.

$\mathrm{Na}$ produção agrícola recorre-se ao uso de substratos artificiais como meio de enraizamento, crescimento e produção de plantas (BUNT, 1983; GABRIELS et al., 1986). O substrato para plantas pode ser entendido como o meio em que se desenvolvem as raízes das plantas cultivadas fora do solo in situ (KÄMPF, 2000), tendo como função primordial, prover suporte às plantas nele cultivadas (FERMINO, 1996; KÄMPF, 2000; RÖBER, 2000), podendo ainda regular a disponibilidade de nutrientes (KÄMPF, 2000) e de água (FONTENO, 1996).

De acordo com Vale et al. (2004), o substrato tem papel fundamental na produção de mudas de qualidade, já que exerce influência marcante na arquitetura do sistema radicular e no estado nutricional das plantas.

Os melhores substratos devem apresentar, entre outras características, ausência de patógenos, riqueza em nutrientes essenciais, textura, estrutura e $\mathrm{pH}$ adequados, além de fácil aquisição e transporte (SILVA et al., 2001). Além disso, Smiderle \& Minami (2001) relacionam que um bom substrato também deve ter retenção de água e porosidade para propiciar difusão de oxigênio necessária para germinação e respiração radicular.

Existem disponíveis no mercado e na natureza diferentes materiais que podem ser usados como substratos, como por exemplo, areia, serragem, solo, casca de arroz carbonizada, vermiculita, entre outros, tornando-se difícil a escolha do melhor (BLOM, 1983; CHEN et al., 1988; GABRIELS et al., 1986). Assim, em função de cada espécie deve-se verificar qual melhor substrato ou combinação destes que proporcionem a formação de mudas de melhor qualidade.

Assim,visou-se com este trabalho avaliar o efeito de diferentes substratos na germinação e no desenvolvimento inicial de jiloeiro ( $S$. gilo Raddi), cultivar Verde-Claro.

\section{MATERIAL E MÉTODOS}

O trabalho foi realizado no Centro de Ciências Agrárias, Universidade Federal do Espírito Santo (UFES), em Alegre (ES), no período de 15 de janeiro a 8 de fevereiro de 2003.
Foram utilizadas sementes de jiló (Solanum gilo Raddi), cultivar Verde-Claro, adquiridas no comércio local. As sementes então, foram semeadas em canteiros, a uma profundidade de $1 \mathrm{~cm}$, utilizando-se espaçamento de $1 \mathrm{~cm}$ entre sementes e $10 \mathrm{~cm}$ entre fileiras, em canteiros cujas dimensões foram de $0,50 \mathrm{~m}$ de largura e $1,0 \mathrm{~m}$ de comprimento. Os canteiros após a semeadura foram cobertos com sombrite.

Foi utilizado o delineamento estatístico inteiramente casualizado com quinze tratamentos, quatro repetições, considerando-se como unidade experimental 100 sementes. Os tratamentos consistiram na utilização dos substratos: resíduos de mineração de calcário com NPK adicional (S1), resíduos de mineração de calcário com NPK e lodo adicional (1:1 v/v) (S2), resíduos de mineração de calcário com NPK e esterco bovino adicional $(1: 1 \mathrm{v} / \mathrm{v})(\mathrm{S} 3)$, resíduos de mineração de calcário com NPK e composto orgânico adicional (húmus de minhoca) (1:1 v/v) (S4), argissolo vermelho-amarelo eutrófico com calagem e NPK adicional (S5), argissolo vermelho-amarelo eutrófico com calagem, NPK e lodo adicional (1:1 v/v) (S6), argissolo vermelhoamarelo eutrófico com calagem, NPK e composto orgânico adicional (húmus de minhoca) (1:1 v/v) (S7), argissolo vermelho-amarelo eutrófico com calagem, NPK e esterco bovino adicional (1:1 v/v) (1:1) (S8), argissolo (pastagem) (S9), solo de várzea (S10); areia lavada (S11), cambissolo haplico eutrófico (S12), substrato comercial (Plantmax ${ }^{\mathrm{R}}$ ) (S13), resíduos de mineração de calcário (S14) e argissolo vermelho-amarelo eutrófíco (S15).

Foram utilizados $0,1 \mathrm{~m}^{3}$ de substrato em cada tratamento. O NPK foi fornecido através da concentração de $50 \mathrm{~g}$ "' $\mathrm{m}^{3}$ de sulfato de amônio, $750 \mathrm{~g}$ "' $\mathrm{m}^{3}$ de superfosfato simples e $50 \mathrm{~g}$ "' $\mathrm{m}^{3}$ de cloreto de potássio.

O lodo utilizado nesse experimento foi proveniente da Lagoa de Eldourado, localizada no município de Serra (ES). O resíduo de mineração de calcário foi coletado na mineradora NEMER, localizado no município de Cachoeira de Itapemirim (ES). O argissolo vermelho-amarelo eutrófico foi coletado na estrada geral que liga os municípios de Cachoeira de Itapemirim e Alegre (ES). Já o argissolo (pastagem) e solo de várzea foram coletados na área experimental da CCA-UFES, Alegre (ES).

Os substratos foram caracterizados quimicamente no Laboratório de Análise de Solo "Raphael M. Bloise", do Centro de Ciências Agrárias da UFES, sendo as análises de macronutrientes, $\mathrm{pH}, \mathrm{Al}, \mathrm{H}+\mathrm{Al}$ e o índice de saturação de bases, realizados conforme metodologia da Embrapa (1999) (Tabela 1).

Ciênc. agrotec., Lavras, v. 30, n. 3, p. 415-421, maio/jun., 2006 
TABELA 1 - Análises de macronutrientes, pH, Al, H+Al e índice de saturação de bases dos quinze substratos utilizados. Universidade Federal de Espírito Santo, Alegre - 2003.

\begin{tabular}{|c|c|c|c|c|c|c|c|c|c|c|c|c|}
\hline \multirow{2}{*}{ Substratos $^{1}$} & pH & $\mathbf{P}$ & $\mathbf{K}$ & $\mathrm{Na}$ & $\mathrm{Ca}^{2+}$ & $\mathbf{M g}^{2+}$ & $\mathbf{A l}^{3+}$ & $\mathbf{H}+\mathbf{A l}$ & $\mathbf{S B}^{2}$ & $\begin{array}{c}\text { CTC } \\
(\mathbf{t})^{3}\end{array}$ & $\begin{array}{l}\text { CTC } \\
(\text { T })^{4}\end{array}$ & \multirow{2}{*}{$\frac{\mathrm{V}^{5}}{(\%)}$} \\
\hline & $\mathrm{H}_{2} \mathrm{O}$ & \multicolumn{3}{|c|}{$\mathrm{mg} \mathrm{dm}^{-3}$} & \multicolumn{7}{|c|}{ cmolc dm ${ }^{-3}$} & \\
\hline S1 & 8,5 & 48,0 & 42,0 & 36,0 & 4,9 & 1,1 & 0,0 & 0,0 & 6,10 & 6,10 & 6,10 & 100 \\
\hline S2 & 8,6 & 34,0 & 35,0 & 36,0 & 4,3 & 0,5 & 0,0 & 0,1 & 4,89 & 4,89 & 4,99 & 98,1 \\
\hline S3 & 8,3 & 37,0 & 29,0 & 34,0 & 3,6 & 0,5 & 0,0 & 0,0 & 4,17 & 4,17 & 4,17 & 100 \\
\hline S4 & 8,3 & 40,0 & 38,0 & 33,0 & 4,1 & 0,6 & 0,0 & 0,0 & 4,80 & 4,80 & 4,80 & 100 \\
\hline S5 & 6,7 & 13,0 & 140,0 & 6,0 & 4,7 & 1,4 & 0,0 & 2,7 & 6,46 & 6,46 & 9,16 & 70,6 \\
\hline S6 & 6,1 & 8,0 & 92,0 & 2,0 & 2,6 & 1,4 & 0,0 & 3,7 & 4,23 & 4,23 & 7,93 & 53,4 \\
\hline S7 & 6,2 & 10,0 & 150,0 & 2,0 & 3,0 & 1,4 & 0,0 & 3,6 & 4,78 & 4,78 & 8,38 & 57,1 \\
\hline S8 & 6,2 & 14,0 & 170,0 & 2,0 & 2,6 & 1,2 & 0,0 & 3,1 & 4,24 & 4,24 & 7,34 & 57,8 \\
\hline S9 & 6,5 & 83,0 & 74,0 & 2,0 & 2,7 & 0,5 & 0,0 & 1,7 & 3,39 & 3,39 & 5,09 & 66,7 \\
\hline S10 & 6,1 & 5,0 & 81,0 & 1,0 & 1,9 & 0,8 & 0,0 & 2,7 & 2,91 & 2,91 & 5,61 & 51,9 \\
\hline S11 & -- & -- & -- & -- & -- & -- & -- & -- & -- & -- & -- & -- \\
\hline $\mathrm{S} 12$ & 7,9 & 24,0 & 66,0 & 3,0 & 4,2 & 0,8 & 0,0 & 0,7 & 5,17 & 5,17 & 5,87 & 88,1 \\
\hline $\mathrm{S} 13$ & 5,4 & 91,0 & 445,0 & 29,0 & 11,8 & 7,1 & 0,0 & 14,6 & 20,04 & 20,04 & 34,64 & 58 \\
\hline S14 & 9,2 & 1,0 & 6,0 & 38,0 & 1,6 & 0,4 & 0,0 & 0,0 & 2,02 & 2,02 & 2,02 & 100 \\
\hline S15 & 7,5 & 66,0 & 110,0 & 6,0 & 5,8 & 1,0 & 0,0 & 0,0 & 7,08 & 7,08 & 7,08 & 91 \\
\hline
\end{tabular}

${ }^{1}$ Resíduos de mineração de calcário com NPK adicional (S1), resíduos de mineração de calcário com NPK e lodo adicional (S2), resíduos de mineração de calcário com NPK e esterco bovino adicional (S3), resíduos de mineração de calcário com NPK e composto orgânico adicional (S4), argissolo vermelho-amarelo com calagem e NPK adicional (S5), argissolo vermelho-amarelo com calagem, NPK e lodo adicional (S6), argissolo vermelho-amarelo com calagem, NPK e composto orgânico adicional (S7), argissolo vermelho-amarelo com calagem, NPK e esterco bovino adicional (S8), argissolo (pastagem) (S9), solo de várzea (S10); areia lavada (S11), cambissolo haplico eutrófico (S12), substrato comercial $\left(\right.$ Plantmax $^{\mathrm{R}}$ ) (S13), resíduos de mineração de calcário (S14) e argissolo vermelho-amarelo eutrófíco (S15).

${ }^{2} \mathrm{SB}=$ Soma de Bases Trocáveis.

${ }^{3}$ Capacidade de Troca Catiônica Efetiva.

${ }^{4}$ Capacidade de Troca Catiônica.

${ }^{5} \mathrm{~V}=$ Índice de saturação de bases.

Aos 18 dias avaliaram-se: porcentagem de germinação (\%), índice de velocidade de emergência (IVE), massa fresca da parte aérea e da radícula (g) e massa seca da parte aérea e da radícula (g). O IVE foi calculado de acordo com Maguire (1962) pela fórmula IVE $=$ N1/D1 + $\mathrm{N} 2 / \mathrm{D} 2+\ldots .+\mathrm{Nn} / \mathrm{Dn}$.

Os dados foram submetidos à análise de variância e comparação de médias pelo teste de Tukey $(\mu=0,05)$, sendo que todos os dados e análises correspondentes foram efetuados com auxílio do programa Genes (CRUZ, 2001).

O IVE foi conduzido com o teste de emergência e suas avaliações realizadas diariamente a partir do surgimento das primeiras plântulas até o décimo oitavo dia. O sistema radicular e a parte aérea foram secos em estufa de circulação forçada a $60^{\circ} \mathrm{C}$, até atingirem peso constante, obtido em 72 horas, para posterior determinação do valor da massa seca do sistema radicular e da parte aérea, sendo realizada a pesagem em balança analítica.

\section{RESULTADOS E DISCUSSÃO}

Pela análise de variância observou-se efeito significativo dos substratos em todas as variáveis analisadas, exceção apenas para massa de matéria seca da radícula (Tabela 2 ).

De acordo com a Tabela 2, maiores valores para germinação foram observados nos substratos S10, S8 e S12. Resultados semelhantes foram obtidos em relação ao IVE, sendo os maiores resultados obtidos com os substratos S10, S8, S12 e S15. Contudo, as menores porcentagens de germinação e IVE foram observadas com os substratos S7 e S6. 
TABELA 2 - Porcentagem de germinação, índice de velocidade de emergência (IVE), massa da matéria fresca da parte aérea (MFPA), massa da matéria seca da parte aérea (MSPA), massa da matéria fresca da radícula (MFR), massa da matéria seca da radícula (MSR) de jiloeiro (Solanum gilo Raddi), cv. Verde-Claro, em quinze substratos ${ }^{1}$. Universidade Federal de Espírito Santo, Alegre - 2003.

\begin{tabular}{|c|c|c|c|c|c|c|c|}
\hline Substratos $^{1}$ & Germinação (\%) & IVE & MFPA & & MSPA & MFR & MSR \\
\hline $\mathrm{S} 1$ & 72,5 abc* & $2,94 \mathrm{abc}$ & 0,78 & $\mathrm{~b}$ & $0,15 \mathrm{~cd}$ & $0,56 \mathrm{~b}$ & $0,04 \mathrm{a}$ \\
\hline S2 & 66,0 abcd & $2,69 \mathrm{abc}$ & 0,63 & $\mathrm{~b}$ & $0,12 \mathrm{~cd}$ & $0,33 \mathrm{~b}$ & $0,03 \mathrm{a}$ \\
\hline S3 & $75,5 \mathrm{ab}$ & $3,10 \mathrm{ab}$ & 0,68 & $\mathrm{~b}$ & $0,14 \mathrm{~cd}$ & $0,46 \mathrm{~b}$ & $0,03 \mathrm{a}$ \\
\hline S4 & $52,5 \mathrm{abcd}$ & $2,15 \mathrm{abc}$ & 0,25 & $\mathrm{~b}$ & $0,56 \quad d$ & $0,33 \mathrm{~b}$ & $0,04 \mathrm{a}$ \\
\hline S5 & $69,5 \mathrm{abcd}$ & $2,86 \mathrm{abc}$ & 0,74 & $\mathrm{~b}$ & $0,13 \mathrm{~cd}$ & $0,10 \mathrm{~b}$ & $0,07 \mathrm{a}$ \\
\hline S6 & $30,0 \quad d$ & $1,24 \quad \mathrm{c}$ & 1,72 & $\mathrm{~b}$ & $0,20 \mathrm{bcd}$ & $0,23 \mathrm{~b}$ & $0,03 \mathrm{a}$ \\
\hline S7 & $31,0 \quad \mathrm{~cd}$ & $1,28 \mathrm{c}$ & 0,63 & $\mathrm{~b}$ & $0,14 \mathrm{~cd}$ & $0,11 \mathrm{~b}$ & $0,02 \mathrm{a}$ \\
\hline S8 & $88,5 \mathrm{a}$ & $3,65 \mathrm{a}$ & 2,09 & $\mathrm{~b}$ & $0,39 \mathrm{bc}$ & $0,48 \quad \mathrm{~b}$ & $0,07 \mathrm{a}$ \\
\hline S9 & 63,0 abcd & $2,59 \mathrm{abc}$ & 0,75 & $\mathrm{~b}$ & $0,22 \mathrm{bcd}$ & $0,13 \mathrm{~b}$ & $0,03 \mathrm{a}$ \\
\hline S10 & $92,0 \mathrm{a}$ & $3,81 \mathrm{a}$ & 2,18 & $\mathrm{~b}$ & $0,47 \mathrm{~b}$ & $0,32 \mathrm{~b}$ & $0,07 \mathrm{a}$ \\
\hline S11 & 41,0 bcd & $1,65 \mathrm{bc}$ & 0,49 & $\mathrm{~b}$ & $0,14 \quad d$ & $0,44 \mathrm{~b}$ & $0,01 \mathrm{a}$ \\
\hline S12 & $84,5 \mathrm{a}$ & $3,50 \mathrm{a}$ & 2,30 & $\mathrm{~b}$ & $0,41 \mathrm{bc}$ & $0,51 \mathrm{~b}$ & $0,05 \mathrm{a}$ \\
\hline S13 & 67,5 abcd & $2,78 \mathrm{abc}$ & $12,02 \mathrm{a}$ & & $1,28 \mathrm{a}$ & 1,46 a & $0,44 \mathrm{a}$ \\
\hline S14 & $77,0 \mathrm{ab}$ & $2,99 \mathrm{ab}$ & 0,12 & $\mathrm{~b}$ & $0,04 \quad d$ & $0,12 \mathrm{~b}$ & $0,01 \mathrm{a}$ \\
\hline S15 & $81,5 \mathrm{ab}$ & $3,38 \mathrm{a}$ & 0,89 & $\mathrm{~b}$ & $0,22 \mathrm{bcd}$ & $0,47 \quad b$ & $0,04 \mathrm{a}$ \\
\hline
\end{tabular}

${ }^{1}$ Resíduos de mineração de calcário com NPK adicional (S1), resíduos de mineração de calcário com NPK e lodo adicional (S2), resíduos de mineração de calcário com NPK e esterco bovino adicional (S3), resíduos de mineração de calcário com NPK e composto orgânico adicional (S4), argissolo vermelho-amarelo com calagem e NPK adicional (S5), argissolo vermelho-amarelo com calagem, NPK e lodo adicional (S6), argissolo vermelho-amarelo com calagem, NPK e composto orgânico adicional (S7), argissolo vermelho-amarelo com calagem, NPK e esterco bovino adicional (S8), argissolo (pastagem) (S9), solo de várzea (S10); areia lavada (S11), cambissolo haplico eutrófico (S12), substrato comercial (Plantmax ${ }^{\mathrm{R}}$ ) (S13), resíduos de mineração de calcário (S14) e argissolo vermelho-amarelo eutrófíco (S15).

*Médias seguidas com a mesma letra nas colunas, não diferem entre si pelo teste de Tukey, a 5\% de probabilidade.

Relacionando os resultados obtidos nestas duas variáveis (\% de germinação e IVE) com as características químicas dos substratos (Tabela 1), constatou-se que os substratos provenientes de resíduos da mineração de calcário (S1, S2, S3, S4 e S14) apresentaram os maiores valores de $\mathrm{pH}$, como já era esperado. Contudo, observa-se que os maiores valores de $\mathrm{pH}$ não afetaram estatisticamente os resultados obtidos no processo germinativo das sementes e no IVE das plântulas de jiló, uma vez que não diferiram significativamente dos demais substratos.
A germinação das sementes pode acontecer em qualquer material que proporcione reserva de água suficiente para o processo germinativo, entretanto, os resultados obtidos podem ser variados de acordo com cada metodologia e/ou substrato ou mistura utilizada.

Entretanto, segundo Fonteno (1996), Handreck \& Black (1999) e Verdonck et al. (1981); o valor do $\mathrm{pH}$ pode afetar consideravelmente o crescimento e o desenvolvimento inicial das plântulas. Este fato foi comprovado no presente trabalho, no qual, observaram-se

Ciênc. agrotec., Lavras, v. 30, n. 3, p. 415-421, maio/jun., 2006 
menores valores da matéria seca da parte aérea nos substratos, que apresentaram valores de $\mathrm{pH}$ superior a 8,3. Larcher (2000) descreve que grande parte da matéria seca acumulada pelas plantas é resultado da atividade fotossintética, e o resto depende da absorção de nutrientes do meio. Conforme Bailey (2000) e Malavolta (1976), a disponibilidade de micronutrientes, como o $\mathrm{B}, \mathrm{Cu}, \mathrm{Fe}, \mathrm{Mn}$ $\mathrm{e} \mathrm{Zn}$ decrescem à medida que se eleva o $\mathrm{pH}$.

Com isso, acredita-se que os valores de $\mathrm{pH}$ superiores a 8,3, observados nos substratos S1, S2, S3, S4 e S14 tenham prejudicado na absorção de nutrientes pela planta, conseqüentemente, proporcionando menores valores no ganho de matéria seca da parte aérea das plântulas.

Em relação as variáveis massa da matéria fresca da parte aérea e da radícula e, massa da matéria seca da parte aérea foram obtidos os melhores resultados com o substrato S13, no qual, refere-se ao substrato comercial Plantmax ${ }^{R}$.

O bom desempenho na formação das plântulas, observado com este substrato pode ser atribuído a seus constituintes químicos. $\mathrm{O}$ valor de $\mathrm{pH}$ deste substrato está dentro da faixa considerada como ideal $(5,4$ a 6,0$)$ para o desenvolvimento e crescimento das plantas ornamentais e hortaliças, conforme descrito por alguns autores, entre eles, Fonteno (1996) e Lopes \& Alonso (1992), podendo assim, ter interferido nestes resultados.

Além disso, no substrato $\left(\right.$ Plantmax $\left.^{\mathrm{R}}\right)$ foram observados os maiores valores de $\mathrm{P}$ e $\mathrm{K}$, que são os macronutrientes, juntamente, com nitrogênio, mais requeridos pela cultura do jiloeiro (BLANCO et al., 1997) e, necessários para bom desempenho das plantas. Segundo Black (1967), o P é o elemento-chave na fase inicial de crescimento devido ao maior acúmulo de biomassa nesta fase.

Lira \& Souza (1992), estudando o efeito de seis substratos no crescimento do limoeiro (Citrus limonia Osbeck cv. Cravo) até a repicagem (135 dias póssemeadura), obtiveram os melhores resultados com os substratos Plantmax ${ }^{\mathrm{R}}$, além dos compostos por Latossolo Vermelho Amarelo Húmico, Latossolo Roxo e Vermiculita ${ }^{\mathrm{R}}$ nas porcentagens 60:16:24 \% e 80:8:12\%.

Conforme pode ser observado neste trabalho houve uma variação na CTC entre os substratos. Estes resultados estão de acordo com Verdonck et al. (1981), no qual descreveram que a CTC pode variar largamente entre os diversos materiais ou misturas usadas como meios de cultivo, desempenhando assim, papel fundamental na reserva de nutrientes para as plantas.
Acredita-se que a alta capacidade de troca de cátions (CTC) apresentada pelo substrato Plantmax ${ }^{\mathrm{R}}$ (S13) possa também estar ligada com a obtenção dos melhores valores nas variáveis massa da matéria fresca da parte aérea e da radícula e massa da matéria seca da parte aérea, sendo estes valores considerado por Alvarez et al. (1999) dentro da faixa considerada como ideal para as plantas.

Para Toledo (1992), um bom substrato para germinação de sementes deve ter elevada capacidade de troca de cátions, além de outras características. A CTC é um importante mecanismo que auxilia na regulação do fornecimento dos nutrientes de cargas positivas para a planta. Além do $\mathrm{pH}$ e da CTC, a maior quantidade de $\mathrm{P}$ pode também estar ligado com estes resultados obtidos com o Plantmax ${ }^{\mathrm{R}}$. Segundo Simão (1998), este nutriente estimula o desenvolvimento da parte aérea das plantas.

Santos et al. (2004), avaliando o efeito de nove substratos na germinação de sementes e na produção de mudas de Solanum sessiliflorum Dunal, obtiveram os melhores resultados com o substrato Plantmax ${ }^{\mathrm{R}}+$ Osmocote.

Já Wagner Júnior et al. (2000), avaliando o uso de três substratos na germinação e crescimento de Tagetes patula, também obtiveram os melhores resultados no crescimento e desenvolvimento de plântulas com o substrato Plantmax ${ }^{R}$. Este resultado também está de acordo com Lopes et al. (1996) e Silva et al. (2001) que relataram a formação de plantas vigorosas de maracujá quando utilizaram Plantmax ${ }^{R}$ em relação à Vermiculita ${ }^{R}$.

\section{CONCLUSÃO}

Os melhores substratos para a germinação de sementes jiló, cv. Verde-Claro foram aqueles em cuja composição havia argissolo vermelho-amarelo com calagem, NPK e esterco bovino adicional, solo de várzea e cambissolo haplico eutrófico. Entretanto, o substrato comercial Plantmax ${ }^{\mathrm{R}}$ foi o melhor substrato na produção da massa da matéria seca das plântulas.

\section{REFERÊNCIAS BIBLIOGRÁFICAS}

ALVAREZ, V. H.; NOVAIS, R. F.; BARROS, N. F.; CANTARUTTI, R. B.; LOPES, A. S. Interpretação dos resultados das análises de solos. In: RIBEIRO, A. C.; GUIMARÃES, P. T. G.; ALVAREZ, V. H. Comissão de fertilidade do solo do Estado de Minas Gerais: recomendações para uso de corretivos e fertilizantes em Minas Gerais: $5^{a}$ aproximação. Viçosa: UFV, 1999. p. 25-32. 
BAILEY, D. A.; FONTENO, W. C.; NELSON, P. V. Greenhouse substrates and fertilization. Raleigh: North Carolina State University, 2000. Disponível em: <http:// ${ }^{\mathrm{W} W W}$ wes.ncsu.edu/depts/hort/floriculture/plugs/, ighsubfert.pdfs. Acesso em: 15 ago. 2000.

BLACK, C. A. Soil plant relationships. 2. ed. New York: J. Wiley, 1967. $792 \mathrm{p}$.

BLANCO, M. C. S. G.; GROPPO, G. A.; TESSARIOLI NETO, J. Jiló (Solanum gilo Raddi). In: Manual técnico

das culturas. 2. ed. rev. e atual. Campinas: [s.n.], 1997. p. 67-70.

BLOM, T. J. Working with soilless mixes, a guide to the different materials characteristics and uses of soilless mixes. Florists Review, Chicago, v. 173, n. 4480, p. 29-34, 1983.

BRASIL. Ministério da Agricultura e Reforma Agrária. Regra para análise de sementes. Brasília, DF: SNDP/ DNDV/CLAV, 1992. 365 p.

BUNT, A. C. Recent developments in soilless media. Span, London, v. 26, n. 1, p. 12-14, 1983.

CHEN, Y.; INBAR, Y.; HADAR, Y. Composted agricultural waste as potting media for ornamental plants. Soil Science, Maryland, v. 145, n. 4, p. 298-303, 1988.

CRUZ, C. D. Programa genes: aplicativo computacional em genética e estatística. Viçosa: UFV, 2001. 648 p.

EMPRESA BRASILEIRA DE PESQUISA AGROPECUÁRIA. Manual de análises químicas de solos, plantas e fertilizantes. Brasília, DF: Embrapa Solos/ Embrapa Informática Agropecuária/Embrapa Comunicação para Transferência de Tecnologia, 1999. 370 p.

FERMINO, M. H. Aproveitamento de resíduos industriais e agrícolas como alternativas de substratos hortícolas. 1996. 90 f. Dissertação (Mestrado em Fitotecnia) Universidade Federal do Rio Grande do Sul, Porto Alegre, 1996.

FILGUEIRA, F. A. R. ABC da olericultura: guia da pequena horta. São Paulo: Agronômica Ceres, 1987. 164 p.
FONTENO, W. C. Growing media: types and physical/ chemical properties. In: REED, D. W. (Ed.). A growers guide to water, media, and nutrition for greenhouse crops. Batavia: Ball, 1996. p. 93-122.

GABRIELS, R.; VERDONCK, O.; MEKERS, O. Substrate requirements for pot plants in recirculating water culture. Acta Horticulturae, The Hague, v. 178, p. 93-99, 1986.

HANDRECK, K.; BLACK, N. Growing media for ornamental plants and turf. Sydney: University of New South Wales, 1999. 448 p.

KÄMPF, A. N. Seleção de materiais para uso como substrato. In: KÄMPF, A. N.; FERMINO, M. H. Substratos para plantas: a base da produção vegetal em recipientes. Porto Alegre: Genesis, 2000. p. 139-146.

LARCHER, W. Ecofisiologia vegetal. São Carlos: Rima, 2000. $531 \mathrm{p}$.

LIRA, L. M.; SOUZA, M. de. Efeito de substratos e do superfosfato simples no crescimento do limoeiro (Citrus limonia Osbeck cv. Cravo) até a repicagem. Ciência e Prática, Lavras, v. 16, n. 2, p. 207-213, 1992.

LOPES, C. C.; ALONSO, E. E. Caracterización química y fisico-química de substratos. In: JORNADA DE SUBSTRATOS, 1., 1992. Actas... [S.1.: s.n.], 1992. p. 19-25.

LOPES, P. S. N.; RAMOS, J. D.; CARVALHO, J. G. de; MORAIS, A. R. de. Efeito da adubação nitrogenada e substratos no crescimento de mudas de maracujazeiro azedo em tubetes. In: CONGRESSO BRASILEIRO DE FRUTICULTURA, 1996, Curitiba, PR. Resumos... Curitiba: [s.n.], 1996. p. 342.

MAGUIRE, J. D. Speed of germination aid in selection and evaluation for emergence and vigour. Crop Science, Madison, v. 2, n. 2, p. 176-177, 1962.

MALAVOLTA, E. Manual de química agrícola. São Paulo: Agronômica Ceres, 1976. 528 p.

PESAGRO-RIO; EMATER-RIO. Recomendações para a cultura do jiló. Niterói, 1989. 16 p. (Informe técnico, 18). 
RÖBER, R. Substratos hortícolas: possibilidades e limites de sua composição e uso: exemplos da pesquisa, da indústria e do consumo. In: KÄMPF, A. N.; FERMINO, M. H. (Eds.). Substratos para plantas: a base da produção vegetal em recipientes. Porto Alegre: Gênesis, 2000. p. 209215.

SANTOS, C. E. M.; RANGEL, R. M.; DIAS, P. C.; MARTINS FILHO, S. Avaliação de substratos na germinação de sementes e produção de mudas de Solanum sessiliflorum Dunal. In: BARBOSA, J. G.; MARTINEZ, H. E. P.; PEDROSA, M. W.; SEDIYAMA, M. A.; Nutrição e adubação de plantas cultivadas em substrato. Viçosa: UFV, 2004. p. 378.

SILVA, R. P.; PEIXOTO, J. R.; JUNQUEIRA, N. T. V. Influência de diversos substratos no desenvolvimento de mudas de maracujazeiro azedo (Passiflora edulis Sims f. flavicarpa DEG). Revista Brasileira de Fruticultura, Jaboticabal, v. 23, n. 2, p. 377-381, 2001.

SIMAO, T. Tratado de fruticultura. Piracicaba: FEALQ, 1998. $760 \mathrm{p}$.

SMIDERLE, O. S.; MINAMI, K. Emergência e vigor de plântulas de goiabeira em diferentes substratos. Revista Científica Rural, Bagé, v. 6, n. 1, p. 38-45, 2001.
TOLEDO, A. R. M. de. Efeitos de substratos na formação de mudas de laranjeira (Citrus sinensis (L.) Osbeck cv. Pera Rio) em vaso. 1992. 88 f. Dissertação (Mestrado em Fitotecnia) - Escola Superior de Agricultura de Lavras, Lavras, 1992.

TOLEDO, F. F.; MARCOS FILHO, J. Manual de sementes: tecnologia de produção. São Paulo: Agronômica Ceres, 1977. 224 p.

VALE, L. S. do; COSTA, J. V. T. da; ANUNCIAÇÃO FILHO, C. J. da; LIMA, R. L. S. de. Efeito de diferentes misturas de substrato e tamanho de recipientes na produção de mudas mamoeiro. In: BARBOSA, J. G.; MARTINEZ, H. E. P.; PEDROSA, M. W. Nutrição e adubação de plantas cultivadas em substrato. Viçosa: UFV, 2004. p. 385.

VERDONCK, O; VLEESCHAUWER, D. de; BOODT, M. de. The influence of the substrate to plant growth. Acta Horticulturae, Wageningen, n. 126, p. 251-258, 1981.

WAGNER JÚNIOR, A.; NUNES, S. F.; CECCONI, A. I.; NUNES, J. C. O.; PEDROTTI, E. L. Efeito de diferentes substratos e volumes de recipientes sobre a germinação e crescimento de Tagetes patula L. In: ENCONTRO NACIONAL DE SUBSTRATOS PARA PLANTAS, 2., 2000, Florianópolis. Resumo expandido... Florianópolis: [s.n.], 2000. p. 38-39. 